\title{
Public Awareness and Preparedness on Local Institutions Coping Strategies towards Natural Disaster Management
}

\author{
Jayamalathi Jayabalan ${ }^{* 1}$, Malathi Nair Narayana Nair², Puvaneswari Veloo³ \\ ${ }^{1,2,3}$ Faculty of Accountancy and Management, Universiti Tunku Abdul Rahman, Kajang, Selangor, 43000, \\ Malaysia.
}

*Corresponding Author: Jayamalathi Jayabalan, Faculty of Accountancy and Management, Universiti Tunku Abdul Rahman, Kajang, Selangor, 43000, Malaysia. jayamalathi@utar.edu.my

\begin{abstract}
Recent years, Malaysia had experienced natural disasters such as landslides and flood. Lack of emergency management when dealing with natural disaster will exacerbate the problem and lead to financial, structural and even human losses. This study intends to examine the impact of coping strategies by local institutions on public awareness and preparedness towards natural disaster management. This research involved an exploratory phase and a detailed reflective phase which covered the Klang Valley. In this study, about 1500 copies of self-administered questionnaires were distributed to the respondents. Questionnaires were collected once the respondents completed the survey. During the reflective phase, in-depth interviews were conducted to measure the level of awareness and preparedness towards natural disaster management of communities. The local residents and residence association representatives were the targeted respondents for the in-depth interviews. The findings of this study are the coping strategies used by local authorities are unsustainable and had not constructed permanent solution in overcoming the growing negative effects of hazards. This research will help promote a safe and secure urban society in Malaysia through a better understanding of the proactive disaster management activities and the significant role of local institutions.
\end{abstract}

Keywords: Natural Disaster Management; Coping Strategies; Local Institution

\section{INTRODUCTION}

Malaysia, like any other country, is affected by natural disasters and suffers from irregular hazards which can be disastrous, it can cause calamitous damages and adversely influence the livelihoods of the affected communities. Fortunately, Malaysia still has not experienced serious disasters till date such as earthquakes, typhoons, volcanic eruptions and etc.

In recent years, not only has the Malaysian Meteorological Department given the statement of global warming due to temperature increase but globally, countries and their related departments also gave the same statement. Global warming has now also become a problem for Malaysia, as it could have detrimental or beneficial impacts on the economic system depending on the sector of operation and geographic positioning, and then there are the combined effects of ' stimuli ' that results with an increase in temperature, for example: wind storms and an increase to rainfall strengths leading to floods. 
According to Siwar, Ahmad and Begum (2013), Malaysia is experiencing a mean surface temperature increase from the range of $0.6^{\circ} \mathrm{C}$ to $1.2^{\circ} \mathrm{C}$ throughout the period of 40 years (1969-2009). Meanwhile, rainfall and river flows are expected to have major instabilities and the surface temperature would increase from $1.5^{\circ} \mathrm{C}$ to $2.0^{\circ} \mathrm{C}$ by 2050 (Siwar et.al.,2013).

In recent years, Malaysia has experienced natural disasters such as landslides and floods. Some areas in Malaysia had recurrences of floods, such as in Terengganu, Kelantan and Pahang. As an example, on $4^{\text {th }}$ December 2011, a flood had occurred at an area in Jalan Tun Ismail which is an area that normally does not experience floods. The recent floods in Kelantan and Pahang had devastating aftermaths in December, 2014. The consequences of these floods had a huge impact to public as a lot of premises, properties and plantations had been destroyed and the communities affected had to live in discomfort. There are many factors that cause floods. The occurrence of floods cannot only be attributed to natural causes. This becomes a major issue as it could cause damages to harvests, properties, public amenities, and others. In addition, lives could be lost if extreme floods occur.

Lack of management when dealing with natural disasters will exacerbate the problem and lead to financial, structural and even casualties. Historically, communities were seen as passive entities whose involvement in disasters/emergencies were only as receivers of assistance when disasters occur. However, community participation has now been recognized as an important element in disaster management that is necessary to reduce the unprecedented consequences from disasters. The destruction has had a grandeur effect on the livelihood of the people and the local communities that are used to coping and developing survival strategies to persevere and respond to the situation before aid is upon them. Currently, communities in Malaysia lack a robust solution to cushion the effects of disasters. Therefore, a study is needed in order to determine the actual causes hence to reduce the effect of floods in the provisioned areas. Preparation for disasters are assessed for their contribution to disaster management assistance. It is therefore important to define disaster preparedness for continuity of disaster planning (Mehrotra, Znati, \& Thompson, 2018); Raman, Ryan, \& Olfman, 2006). According to Adger (2006), adaptive capacity is a constitute of both resilience and vulnerability. In order to strengthen communities' capacities to achieve sustainable well-being, resilience or a decrease in vulnerability approaches are important elements.

The findings of the research will help promote a safer and a more secure urban society in Malaysia through a better understanding of the proactive disaster management activities and the significant role of local institutions. This study is aimed at ensuring that the government is constantly ready and able to serve the individual citizen's changing needs as the nation seeks to foster a knowledgeable society. The outcome of this research will be optimistic and beneficial to the government of Malaysia in particular Majlis Keselamatan Negara (National Crisis Committee) as disaster management requires government intervention and a proper planning as well as funding for community preparedness programmes for disasters.

Natural disasters come in all sorts of forms. The same is true for fear. The ways in which individuals are affected by, or in the aftermath of, a potential natural disaster is different and unique to each person. No one witnesses the same thing. Everyone has a way, based on their individual experiences and other variables, to view the universe. "Disaster coping capability" refers to the holistic operational capacity of the local people to learn how to deal with disasters in case of an emergency through the cooperation of all members of the community, which relies not solely on concrete solutions but also on the potential coping capacity embedded in the day-to-day relationships and community cohesion.

\section{LITERATURE REVIEW}

As Malaysia constantly develops, governments, businesses and the general public need to keep pace with changes and disasters that have an effect on the sustainability of the society. Disaster preparedness is an initiative aimed at increasing risk readiness and awareness amongst various stakeholders, relevant agencies on safety precautions and other information on disaster-related preparations. This focuses on 
improving the overall preparedness for hazards at the very least the sort of disaster that would be likely to occur in a specific location. This research is aimed at promoting ' community resilience, ' that is, helping communities to remain resilient to disastrous events. The public's increasing sensitivity to the environmental and safety concerns has raised awareness of these scenarios (Salzano, Basco, Busini, Cozzani, Marzo, Rota \& Spadoni, 2013). Awareness of risks and dangers must be implemented in the early stages of education before these skills can become an aspect of civic and professional obligations as people mature (Shiwaku and Shaw, 2008).

Communities can face environmental stressors unrelated to their prior knowledge (Adger, Huq, Brown, Conway, \& Hulme, 2003). Strategies to overcome with various stressors are vital (Berman et.al, 2014). Du, Kobayashi, Okazaki, and Ochiai (2016), in his recent studies on the residents of Shangli Village in China, it has been found that they still have no clear understanding of responses to natural disasters. However, they rely mostly on intuition according to their individual experience. A similar study concluded that the residents were better prepared for their households, but depend on the government for public preparedness. "Coping" has been described as the way people act within existing resources and the set of people's perceptions of a situation to achieve different ends (Brahmi \& Poumphone, 2002). Due to problems exacerbated by climate change and uncertainty, communities among the developing countries use a range of coping strategies to address impoverishment, conflict, lack and insecurity of food and environmental stress (Berman et.al, 2014). Based on the short but intense literature review, this study aims to examine the influence of coping strategies by local institutions on public awareness and preparedness towards natural disaster management.

\section{METHODOLOGY}

This research involved an exploratory phase and a detailed reflective phase which covered the Klang Valley with the aim to investigate the impact of coping strategies by local institutions which influence awareness and preparedness among the local communities towards natural disasters. During the reflective phase, in-depth interviews were conducted to measure the level of awareness and preparedness towards natural disaster management of communities. The local residents and residence association representatives were the targeted respondents for the in-depth interviews. In this study, about 1500 copies of self-administered questionnaires were distributed to the respondents. Questionnaires were collected once the respondents completed the survey. In-depth interviews were conducted after making appointment with the respondents. A total of 13 local residents and resident representatives were interviewed to obtain their perception on the level of awareness and preparedness towards the issue of natural disasters in the Klang Valley.

The second phase was a questionnaire survey to better understand or build a more comprehensive understanding of the research issue through separate yet complementary data. The respondents for the survey questionnaire were aged between 13 to 65 years old and were selected from various parts of Klang Valley. The reason this study was focused in Klang Valley is because, out of 30.7 million of total population in Malaysia, $25.8 \%$ are located at Klang Valley which stands the highest percentage of populations (www.dosm.gov.my). In this study, convenience sampling has been utilized as it is easier to recruit respondents to answer and return back the distributed questionnaires efficiently and effectively. With convenience sampling, a large amount of the completed questionnaires can be collected (Sedgwick, 2013) and more in-depth interviews could take place. Based on Collis and Hussey (2013), it is noted that a good research requires a larger sample size.

Overall, three scales have been emphasized in this study to test reliability and validity of the hypothesis and data results which are the interval scale, nominal scale and ordinal scale. Interval scale is a measurement technique in which the attributes of a variable can be labeled, ranked, and the distance between the attributes is known. Hair et al. (2007) states that interval scales having the highest measurement level. With this interval scale, parametric statistic techniques can be studied such as mean and standard deviation of responses on the variables. The nominal scale is the type of scale in which the 
numbers or alphabets assigned to items are used as identification or cataloguing labels (Zikmund, 2003). Lastly the ordinal scale is a measurement where data is in order of ranking. Section A applied this form of scale measurement. For instances the ordinal scales level of measurement is arranged accordingly from younger age to older age. Cronbach's Alpha was used to test the reliability of data. The reliability coefficient of alpha was normally range from 0 to 1.0 (Zikmund et al., 2013). The alpha value was significant if it was greater than 0.7 (Lacobucci \& Duhachek, 2003). The higher the alpha values are to 1.0, the greater the reliability of the data (Sekaran \& Bougie, 2013).

The questionnaire was designed with an interval scale with a 5-point likert scale. Respondents can state their level of agreement by responding to questionnaire items (Evens, Schuurman, De Marez, \& Verleye, 2010). Questions for coping strategies by local institutions in the questionnaire were adopted from Gerdan (2014) research in order to maintain the validity and relevancy of the questionnaires using five-point likert scale $(5=$ strongly agree, $4=$ =agree, $3=$ =neutral, $2=$ disagree and $1=$ strongly disagree). The nominal scale served as a non-calculation method which emphasized quality more than quantity by allocating subjects into categories or group of variables. The questionnaire has been divided into two parts, Section A and B. Section A consists of a demographic profile of targeted respondents which was measured through the nominal and ordinal scale. Questionnaires in Section B were constructed by the using interval scale and the scale of measurement used is 5 points likert scale ( $5=$ =strongly agree, $4=$ agree, $3=$ neutral, $2=$ disagree and $1=$ strongly disagree) because 5 -point likert scale has higher reliability than 4 point likert scale (Croasmun \& Ostrom, 2011).

\section{Discussion}

\section{Coping strategies by local institution}

In response to the items asked while participants were being interviewed on the role of local councils, early warnings and communications between communities and councils during disasters and its effectiveness and the local governments participation in disaster-related matters, a range of reasons were offered, including:

\section{Role of Local Council}

The result will provide the extend of external support from the local council in coping with natural disasters such as landslides and floods; is an effective strategy to help communities reduce the impact of disasters. More than half of the respondents thought that some methods that the local council used in coping with natural disasters were impractical and did not established lasting security. They also mentioned that it has been a long-standing problem till now. One of the respondents added that the Municipal Council contractors are not cleaning the drainage. In fact, there must be a supervisor or any relevant council representative to meet up with residents occasionally every quarterly to discuss on improvements. The residents are not satisfied as the local council cannot find effective solution for the flood but only make promises. According to a respondent, "the main monsoon drains and retention ponds do not work. The authorities do not bother as it is an on-going problem for more than 10 years". However, a few of them commented that even though the local council are trying their level best to tackle the problem but still improvement is needed. They mentioned that cleaning the drains regularly, collection of rubbish and educating people on disaster management is important. They commented that houses, roads, driveways, and parking lots are being designed to maximize runoff by reducing the amount of rain the earth absorbs.

The results also showed that some of the respondents believe the local community has a 'wait and see' culture in which prevents them from finding effective and immediate solutions. One of the respondents supported this opinion, explaining that some of the early steps taken to put up sand bags up 
till about shoulder height along the river is only a temporary measure rather than building a wall along the river to prevent flood.

\section{Effectiveness of Early Warning System and Communication Systems}

The emergency response plan for disaster preparedness is an important element. It is necessary to have awareness of different social groups and their vulnerabilities among local authorities. The local authority can therefore determine its ability and resources to mitigate the consequences of disasters. Local development policies, management systems, technical expertise, equipment, communication systems, facilities, and relationships may include these capacities and resources. In the wake of a tragedy, successful emergency response by local authorities plays a significant role in saving lives. On the other hand, in the event of a delay in external aid due to exclusion of affected areas, lack of capacity at the local level for disaster management may result in massive casualties and an overall mass destruction of local properties. Early warnings and early actions can often prevent a threat from becoming a human tragedy by attempting to prevent casualties and reducing the economic and environmental impacts.

We also surveyed perspectives of the respondents on the early stages of the warning system. Most of the respondents claimed that there were no pre-emptive warnings and communication between communities and councils. Local residents are still struggling with flooding issues individually or by partnering with their neighbours, thus reducing their efforts' effectiveness. According to them, the capacity of local authorities to alert and rescue residents affected by floods has been portrayed as limited. Each time that heavy rains occur, the drainage system has proven to be and there will be high possibility for flood. Heavy rain can sometimes lead to flooding for a very short time and can occur within a very short time (2-6 hours, and sometimes within minutes). One of the respondents who is a condominium resident commented that the management has staffs to check around the condo for water ponding usually at the car park area. Two other respondents commented that they had received a warning through word of mouth but it was too late.

Local authorities should implement an effective early warning system to alert all residents of a possible flood risk in the region in advance. One of the residents felt they were not informed when there is an emergency. He further added that "there must be a system, like sirens or alerts from the Resident Associations; I am not adequately informed about the plans for emergencies. Preferably a SMS could help to give information. Disaster strikes without warning so all the support agencies should be alert and find ways to inform people". Many interviewees are of the opinion that they are not adequately informed. Some commented most of the time they will get to know through neighbours. To sum it up, there was hardly any warning given to or by the people.

Normally help comes only after the disaster, E.g. SYABAS will distribute water and local councils will come to repair the roads. According to a condominium resident, the guards are trained to respond to emergencies and have a list of phone numbers to call (medical, criminal, fire etc). They use the intercom system where it is connected from the homes of the residents to the guardhouse. In case of an emergency, the guards will inform the residents in person. The respondents suggested that in the future, the local authority should upload information on the internet/website about where to assemble and what are the necessary procedures/checklists when flood occurs. This way, the local authorities have a major role to play. In certain areas of disaster risk reduction, they will develop the capacity of local communities.

Local Government Participation in Disaster-Related Issues

Generally, many respondents felt that local councils or community leaders have not met the needs of the residents in terms of disaster management. One of the residents mentioned that "this area has many old residents, especially retirees. Many had to leave their cars and houses when the floodwaters rose. What if a tragedy had occurred, like an old person slipping and falling? We are paying quit rents and 
assessments yearly. How is this fair to the residents"? Many interviewees claimed that existing planning regulations lack the Disaster Risk Reduction (DRR) planning element which can be the cause of a major barrier. As mentioned by one of the interviewees, it is presumed that such plans are not executed by sufficient local staff, and sometimes these plans are overruled and never enforced. As such, interviewees claimed that local governments are not interested in the risk reduction activities of their region, but are actively involved in post-disaster operations.

Another major challenge was the lack of disaster awareness and risk reduction. The community is therefore not very interested in this topic and does not fully understand the need for DRR. They are therefore, not prepared to spend extra money on unique DRR initiatives. It is very important to educate the community about the consequences of disasters and to make them aware of their negative effects if preventive action is not taken into account.

According to one of the respondents, only three months back, the residential association formed a WhatsApp group amongst residents and councillors but as per usual comments were voiced out to no affiliation by the residential association. However, the respondent added that "the residents here have a WhatsApp group to update each other but we do not have any "prepared community models" like evacuation routes and designated evacuation sites. ". We do feel that we can organise a disaster resilient village's programme, conduct training and create a simulation for the community. Most of the respondents condemned the inadequate participation of local authorities in disaster-related issues.

Most of the respondents felt that the local council has not provided sufficient protection and public education to increase awareness and community capacity. Local authorities ought to be more vigilant about flood victims and they should not take their situation lightly. One of the respondents suggested that there is room for improvement if the local council employs a consultant to study flooding mitigation problems in their area. He added that even though his area is prone to having floods, yet no actions were taken and they have not participated in any training or awareness activities. Local governments, local leaders, NGOs, mosques, churches, and temples should not only engage in post-disaster relief operations, but should also participate actively before the flood in particular to educate people and build a common strategy on how to avoid and cope with flooding in each community.

One of the condo residents commented that some of the residents have the insensitivity and so called "tidak-apa" attitude and reluctance to attend talks despite being informed of its importance. A few of which even reported of there being no substantial effort and initiative from the local authority, people are not aware as there is low publicity. However, the community does partake in "gotong royong" activities organised by the local council but the numbers are unreasonably low. One of the respondents commented that his family had installed metal cabinets after the flood incident to safeguard their firstfloor belongings as a method to shield themselves when their ground floor is submerged in water. Most of them have taken precautionary steps such as building raised steps, concrete blocks and raised building to avoid the effects of floods, as a few of them had to cash in more money to raise their kitchen floor.

A few residents argued after so many complaints and media intervention, they have now obtained a minor amount of allocation from the federal government to construct more retention ponds that are bigger in size and upgrade the drainage system. The local council decided to build an extra flood gate and also a retention pond to address the immediate problem. However, for a long-term solution, a study is needed on rain patterns in a particular area which coincides with the terrain of the area. Another resident mentioned that now councillors have started to play extra roles such as cleaning the clogged drains frequently and when there is a downpour, immediately checking whether the existing pumps are functioning to push the water into retention ponds. He suggested a frequent brainstorming session amongst the neighbourhood and the local council could be better. Local area demographic analysis allows local authorities to understand the community's capacity and resources as a whole. Natural resource assessments must also be carried out to identify potential opportunities for disaster prevention through restoration and protection of the environment. 


\section{RESULTS AND FINDINGS}

In conclusion, there was no effective early flood warning system in place by local authorities. Most people claimed that they were not getting flood warnings. The approach to flood control by the authorities is top-down, with little participation in flood-related planning by local residents. There is no organised method to warn people about impending disasters. Nonetheless, without the active involvement and participation of vulnerable communities, local authorities alone cannot achieve greater success in the prevention, preparedness and response to disasters, as efficient disaster risk reduction requires participation by all vulnerable individuals, families, communities and organizations. For Malaysians, the level of awareness and preparedness to climate change and natural disasters is still minor and citizens' views on the impact of natural disasters and acted upon on issues of natural disasters are also low and weak, with a vast majority still maintaining a reactive, rather than a proactive attitude. Some common questions posted are: "what is that?" and "what we need to do and adapt to it?" Interviews, however, showed how important it is to increase community resilience and capacity building. The recommendation is to have public education and training on flash flood hazards and landslides, and development of evacuation routes. Consequently, the most promising risk reduction approach incorporates planning measures with early warning technologies, which would result in fewer losses from future flash floods and landslides.

As for quantitative research, research questions were tested using SPSS 24.0. This software has been used to analyse the data obtained from the questionnaires that the target respondents filled out. Descriptive analysis is undertaken to explain the characteristics of sample (Sekaran, 2003). Descriptive Analysis is used to characterize the research interest phenomenon involving the conversion of raw data into a type that would provide information about a set of factors in a situation (Sekaran, 2003). The summary of data is usually done by average calculation, frequency distribution and percentage distribution. In this research, characteristics of respondents were analysed base on the result of the questionnaires received. Table 1 shows how respondents rated the five statements. Statement 5 has the highest mean which is 3.0. Meanwhile, Statement 1 has the lowest mean of 2.65. Besides, statements that have highest percentage score of disagree are Statement 1 which is $36.7 \%$ and the statement with the lowest score is Statement 5 which is $25 \%$. In addition, Statement 3 has almost similar percentage of disagree and neutral of $30.4 \%$ each. The survey also revealed that not all coping strategy by the local council were well received by the respondents. Statement 1 were least supported by respondents, with a mean score of 2.65 respectively.

Table 1: Central Tendencies Measurement of Coping Strategy

\begin{tabular}{|c|c|c|c|c|c|c|c|}
\hline Statement & SD & D & $\mathbf{N}$ & A & SA & Mean & Std. Dev. \\
\hline \multicolumn{8}{|l|}{ My local council or community has an Annual } \\
\hline $\begin{array}{l}\text { Public Awareness Campaign to increase the } \\
\text { general population understanding on natural } \\
\text { hazards. }\end{array}$ & 10.3 & 36.7 & 31.8 & 19.9 & 1.3 & 2.65 & 0.953 \\
\hline $\begin{array}{l}\text { My local council or communities have regular } \\
\text { exercise on disaster preparedness practice } \\
\text { drills. }\end{array}$ & 9.3 & 30.6 & 30.5 & 25.2 & 4.4 & 2.85 & 1.041 \\
\hline $\begin{array}{l}\text { My local council or community have a natural } \\
\text { disaster recovering funding strategy. }\end{array}$ & 7.9 & 30.4 & 30.4 & 28.4 & 2.9 & 2.88 & 1.003 \\
\hline $\begin{array}{l}\text { My local council have a coping strategy in } \\
\text { emotional comforting. }\end{array}$ & 7.4 & 29.3 & 31.9 & 27.7 & 3.7 & 2.91 & 1.003 \\
\hline $\begin{array}{l}\text { My local council have proper maintenance of } \\
\text { the catchment areas/barricade/walls. }\end{array}$ & 5.8 & 25.0 & 35.6 & 30.6 & 2.9 & 3.0 & 0.952 \\
\hline
\end{tabular}




\section{CONCLUSION}

Despite being prone to natural disasters, Malaysia's awareness of such disasters is remarkably low, as shown by the scarcity of educational materials on preparedness for natural disasters and community mitigation. At present, very little attention has been given to this topic in the school curriculum. The development of educational materials for the planning and prevention of natural disasters will therefore play an essential role in the implementation of the UN Decade of Education for Sustainable Development in Malaysia. Even though respondents hold a high level of education but they still show low awareness and preparedness for natural disasters. Therefore, it further strengthens the argument in previous literature review about early education on natural disasters is important (Shiwaku and Shaw, 2008).

The analysis of the in-depth interviews has also created recommendations to tackle issues in natural disaster management. As evidenced in the literature and expert interviews as well as the survey, strategies used by local authorities to cope with the rising negative effects of hazards are unsustainable and still have not created a permanent solution. Local authorities are facing massive challenges in contributing to the resilience of cities as the role and responsibilities of local government decrease. Currently, the local government has a limitation to make decisions as decision making has now been passed to the control of state or the federal government. Hence, the local governments in Malaysia have a limited authority and they are unable to put up an initiative with respect to disaster risk management. Local governments also lack adequate information about their communities ' disaster threats and vulnerabilities as well as appropriate measures for disaster risk reduction. Therefore, it is near impossible for local authorities to initiate a disaster resilient built environment within the city, when they have not been provided with appropriate training or education concerning disaster risk management matters. Several initiatives can be taken to raise community awareness including the following:

1. Collecting and monitoring data on seasonal weather patterns over time,

2. Creating proper database on the impacts and social changes over time due to disaster for record keeping such as local hazards, livestock, and environmental changes,

3. Proper preparation of resources for threats, hazards and disasters,

4. Sharing of knowledge about disaster risks and vulnerabilities between communities and authorities,

5. Formal support and approval to include knowledge and disaster preparedness in planning, and social development programs for the communities,

6. Good communication of danger and threat between local authorities and communities.

The change from preparedness to mitigation-oriented approach should be regarded by local authorities as one of the effective strategies to mitigate the impacts of disasters. In the meantime, it is important to keep their knowledge up to date and resources in terms of disaster threat and to have a good system of communication between all relevant stakeholders so that they can enforce them at the city level. So far, the issue of disaster risk management in Malaysia as a whole has not been given its due importance and it is hard to identify clear efforts aimed at the protection and promotion of disaster preparedness and resilience at all levels. Local authorities therefore need to identify, evaluate and track disaster risks and enhance early warnings to reduce underlying disaster risk factors. Besides, local authorities as well as related resident-bodies must take a more proactive approach when facing the challenge of creating awareness amongst urban residents by taking a more proactive approach. Since some residents have their own social groups, local authorities can make use of social media as well as modern communication channels such as WhatsApp to promote awareness among communities. In this study the respondents presented several examples of common coping strategies used to tackle the impacts of climate change. For further studies, there is a need to do a comparative study between respondents from other states which have experienced the prolonged or frequent natural disaster. This 
may provide further insight of how the communities' engagement activities are carried out as well as the level of participation from different communities.

\section{Reference:}

Adger N. Vulnerability. Global Environmental Change. 2006; 16:268-281.

Adger, W. N., Huq, S., Brown, K., Conway, D., \& Hulme, M. (2003). Adaptation to climate change in the developing world. Progress in Development Studies, 3(3), 179 -

Berman, R. J., Quinn, C. H., \& Paavola, J. (2015). Identifying drivers of household coping strategies to multiple climatic hazards in Western Uganda: implications for adapting to future climate change. Climate and Development, 7(1), 71-84.

Brahmi, A., \& Poumphone, K. (2002). Study on Local Coping Mechanisms in Disaster Management. Laos: Concern.

Collis, J., \& Hussey, R. (2013). Business research: A practical guide for undergraduate and postgraduate students. Macmillan International Higher Education.

Croasmun, J. T., \& Ostrom, L. (2011). Using Likert-Type Scales in the Social Sciences. Journal of Adult Education, 40(1), 19-22.

Du, F., Kobayashi, H., Okazaki, K., \& Ochiai, C. (2016). Research on the disaster coping capability of a historical village in a mountainous area of China: case study in Shangli, Sichuan. ProcediaSocial and Behavioral Sciences, 218, 118-130.

Evens, T., Schuurman, D., De Marez, L., \& Verleye, G.(2010). Forecasting broadband Internet adoption on trains in Belgium. Telematics and Informatics, 27(1), 10-20.

Hair, J. F. (2007). Research methods for business.

Harrington, A. (2005). Modern Social Theory. 1-13.

Harris, A. L., Lang, M., Yates, D., \& Kruck, S. E. (2008). Incorporating Ethics and Social Responsibility in IS Education. Journal of Information Systems Education, 22(3), 183-189.

Harun, R., Hock, L. K., \& Othman, F. (2011). Environmental Knowledge and Attitude among Students in Sabah. World Applied Sciences Journal, 14, 83-87.

Lacobucci, D., \& Duhachek, A. (2003). Advancing alpha: Measuring reliability with confidence. Journal of consumer psychology, 13(4), 478-487.

Mehrotra, S., Znati, T., Thompson,W. C. (2008). Crisis management. IEEE Computer Society, 1089-7801, 14-17.

Murphy, T. and Jennex, M.E. (2006). Knowledge Management, Emergency Response, and Hurricane Katrina, International Journal of Intelligent Control Systems, 11(4), pp. 199-208.

Raman, M., Ryan, T., \& Olfman, L. (2006). Knowledge Management System for Emergency Preparedness: An Action Research Stud. Proceedings of the 39th Hawaii International Conference on System Sciences - 200

Salzano, E., Basco, A., Busini, V., Cozzani, V., Marzo, E., Rota, R., \& Spadoni, G. (2013). Public awareness promoting new or emerging risks: Industrial accidents triggered by natural hazards (NaTech). Journal of Risk Research, 16(3-4), 469-485.

Sedgwick, P. (2013). Convenience sampling. Bmj, 347, f6304.

Sekaran, U. (2003). Research methods for business, NY.

Sekaran, U., \& Bougie, R. (2013). Edisi 6. Research Methods for Business.

Shiwaku, K., \& Shaw, R. (2008). Proactive co-learning: a new paradigm in disaster education. Disaster Prevention and Management: An International Journal, 17(2), 183-198.

Siwar, C., Ahmed, F., \& Begum, R. A. (2013). Climate change, agriculture and food security issues: Malaysian perspective. Journal of Food, Agriculture and Environment, 11(2), 1118-1123.

Zikmund, W. G. (2003). Business research methods 7th ed., Thomson/South-Western.

Zikmund, W. G., Babin, B. J., Carr, J. C., \& Griffin, M. (2013). Business research methods. Cengage Learning. 